\title{
Effect of nutrient and pre-infested brinjal, Solanum melongena by whitefly and aphid on population dynamics of whitefly, Bemisia tabaci
}

\author{
Mohd Rasdi Zaini, Che Salmah Md Rawi, Abu Hassan \\ School of Biological Sciences, Universiti Sains Malaysia, Penang, Malaysia
}

Email address:

dddpim@pahang.uitm.edu.my (M. R. Zaini),csalmah@usm.my (Che Salmah Md Rawi), aahassan@usm.my (Abu Hassan)

To cite this article:

Mohd Rasdi Zaini, Che Salmah Md Rawi, Abu Hassan Ahmad. Effect of Nutrient and Pre-Infested Brinjal, Solanum Melongena by Whitefly and Aphid on Population Dynamics of Whitefly, Bemisia Tabaci. Agriculture, Forestry and Fisheries. Vol. 2, No. 1, 2013, pp. 1-10. doi: 10.11648/j.aff.20130201.11

\begin{abstract}
This study investigated the consequence of nutrient concentration levels and pre-infestation of brinjal (Solanum melongena) plant (by whitefly and aphids) on population of whitefly (Aleyrodidae; Hemiptera) over two cropping periods. Both factors, nutrient levels and pre-infestation by pests could also change plant-pest relationship especially with herbivorous insect pests. Variation in nutrient levels applied to the plants could influence different physiological performance of the plants which subsequently affected whitefly population. Populations of whitefly were higher following increasing levels of nutrients in non-pre-infested (control) plants. Lower whitefly populations were observed on whitefly pre-infested brinjal plants compared to aphid pre-infested and control plants. Pre-infested plants were suspected to induce productions of secondary metabolites as a chemical defense system thus lowering the number of whiteflies on them. Considering other management technique in controlling whiteflies on brinjal such as optimum nutrient supplement as plant growth progress and good pest care during seedling stage was proposed.
\end{abstract}

Keywords: Whitefly, Bemisia tabaci, Pre-Infestation, Nutrient, Population Dynamic, Brinjal

\section{Introduction}

Whitefly (Aleyrodidae: Hemiptera), a pest to more than 500 plant species, have been recorded since 18th century [1]. Whitefly adults oviposit under surfaces of young leaves [2 and 3] and after eclosion, the first instar nymphs (crawlers) move a short distance over the leaf surface to find a suitable feeding site. Once settled, they continue feeding but remain sessile until they grow to adult stage [2]. At high densities, whiteflies are active pests on several host plants such as brinjal (Solanum melongena L.), tomato (Solanum lycopersicum) and chillies (Capsicum annum). Brinjal is one of the most popular fruit vegetables grown extensively throughout Malaysia. This fruit vegetable is originated from India but it is currently planted in both tropical and subtropical countries. Applying excessive amount of insecticides and fertilizers has been a common practice to farmers in Malaysia to improve yield production. Over use of chemicals is known to cause serious damage to ecological system and to human health [4].

High diversity of plants and insects leads to complex interactions in multitrophic systems. Some plants produce different chemical defenses to combat different species of pests [5]. Variation in nutrient levels applied to the plants could influence different physiological performance of the plants [6]. It could also change plant-pest relationship especially with herbivorous insect pests [7] or alter pest populations [8]. Usually insect-pests are more abundant in agricultural habitats than in native habitats [9]. Most plants response to pest attacks by producing secondary metabolites or initiating enzymes activities to generate chemical defense [10]. The plants-pest interactions on various plant species also result in different sizes of pest population and species composition on the plants [8]. Information on the plant-pest and other trophic level interactions is crucial in developing IPM strategy for insect pests of brinjal. This study was undertaken to address issues on plant-pest interaction. The main objectives of this study were to (1) evaluate the effect of different nutrients concentrations on brinjal plants in relation to whitefly infestation, (2) assess the effect of early infestation of on young plants (seedlings) on whitefly population infesting brinjal plants and (3) evaluate the plant resilience at different phenological stage (time) to whitefly infestation. 


\section{Materials and Methods}

\subsection{Study Area}

Malaysia has year round equatorial climate with high rainfall (26 $\mathrm{mm}$ to $359.2 \mathrm{~mm}$ mean/ month) and relative humidity of $70-85 \%$ and temperature of $30 \pm 5^{\circ} \mathrm{C}$ (Malaysia Meteorological Department, Bayan Lepas, Penang). This experiment was carried out for 2 cropping periods at Agriculture Centre, Relau, Pulau Pinang, Malaysia with three months sampling period from August to October 2010 and between February and May 2011 for first and second crops respectively. Brinjal plants are planted in polybags containing burnt rice husk (soilless medium) under a rain shelter to protect brinjal (Solanum melongena $\mathrm{L}$ ) plants from hazardous effect of rainfall. The rain shelter was equipped with a fertigation system.

\subsection{Stock Culture of Whiteflies and Aphids}

Whitefly adults were collected from honeydew melon (Cucumis melo var. Cantalupensis) planted under a rain shelter at Agriculture Centre, Relau, Penang and maintained in the USM Entomology laboratory on brinjal plants at an ambient temperature of $26 \pm 2^{\circ} \mathrm{C}, 80 \% \pm 5$ Relative Humidity, and a photoperiod of $\pm 12: 12$ (L:D). A brinjal plant with fifty whitefly adults were placed in each of two wooden rearing cages $(50 \mathrm{~cm} \times 45 \mathrm{~cm} \times 60 \mathrm{~cm}) \quad$ covered by wire netting $(0.5 \mathrm{~cm} \times 0.5 \mathrm{~mm})$ to provide ventilation as well as to prevent the escape of the insects. Aphids were collected from brinjal plants planted by farmers around Penang Island. Approximately two hundreds aphids were also placed in a cage for mass rearing. The cages were lighted (12-14 hours daily) with a 12 volt fluorescent light on top of each cage.

\subsection{Preparation of Brinjal Plants}

Standard agronomic practices such as drip irrigation, seed germination, fertilization, pruning and harvesting were employed in this study for ideal growth of brinjal plants and normal distribution of Bemisia tabaci and its natural enemies. Selected F1-hybrid brinjal seeds were sown in seedling trays covered by pieces of wire nets to avoid undesirable insect infestations. The trays were placed in the nursery at the School of Biological Science, Universiti Sains Malaysia. After three weeks, 180 brinjal seedlings were selected and divided into three groups; (1) the first group was infested by whitefly (60 plants), (2) the second group was infested by aphid (60 plants) and (3) the third group of seedlings (60 plants) were not infested with any pest and used as a control. A week after the infestation, 15 brinjal seedlings were chosen from each group with a total of 45 plants. The seedlings (4-week-old) were transplanted carefully into polybags (each measuring $30 \mathrm{~cm} \times 30 \mathrm{~cm}$ ), containing burnt rice husk. The poly bags were arranged in five blocks at one meter apart between plants and one meter between blocks under the rain shelter equipped with a fertigation system.

\subsection{Treatments of Brinjal Plants}

Two combinations of treatments applied to the brinjal plants; (1) application of three concentrations of nutrients, $50 \mathrm{ppm}, 150 \mathrm{ppm}$ and $300 \mathrm{ppm}$ and (2) Infestation of brinjal seedlings (pre-infestation of plants) by whitefly and aphids. The combination treatments were defined as N1TC $(\mathrm{N} 1=50 \mathrm{ppm} ; \quad \mathrm{TC}=\mathrm{Non} \quad$ pre-infested/control); $\quad \mathrm{N} 2 \mathrm{TC}$ (N2=150ppm; $\quad \mathrm{TC}=$ Control); $\quad \mathrm{N} 3 \mathrm{TC} \quad(\mathrm{N} 3=300 \mathrm{ppm}$; $\mathrm{TC}=$ Control); N1TW $(\mathrm{N} 1=50 \mathrm{ppm} ; \mathrm{TW}=$ pre-infested by whitefly); N2TW (N2=150ppm; TW=pre-infested by whitefly); N3TW (N3=300ppm; TW=pre-infested by whitefly); N1TA (N1=50ppm; TA=pre-infested by aphid); N2TA (N2=150ppm; TA=pre-infested by aphid); N3TA (N3=300ppm; TA=pre-infested by aphid) [11].

\subsection{Treatment 1 (Nutrient Levels)}

\subsubsection{Preparation and Application of Nutrients to Brinjal Plants}

All raw materials for nutrients mixture were supplied by the Department of Agriculture (DOA), Relau, Penang. The nutrient compositions and concentrations used in this study were based on common practices recommended by Malaysian Agricultural Research and Development Institute (MARDI) and Department of Agriculture Malaysia. Two sets of nutrient mixtures were prepared. Set A consisted of $900 \mathrm{~g}$ Calcium nitrate $(\mathrm{Cn}-46 \%)$ and $41.6 \mathrm{~g}$ Iron EDTA (Fe-2.15\%). Set $\mathrm{B}$ was made of $152 \mathrm{~g}$ potassium nitrate (Pn-7.87\%), 500g magnesium sulphate (MgSO4-25.89\%), $320 \mathrm{~g}$ potassium chloride $(16.57 \%), 13.6 \mathrm{~g}$ phosphoric acid $(0.7 \%), 0.1 \mathrm{~g}$ zinc sulphate $(0.05 \%), 0.1 \mathrm{~g}$ cuprum sulphate $(0.05 \%), 0.4 \mathrm{~g}$ ammonium molibdate $(0.02 \%), 2 \mathrm{~g}$ manganese sulphate $(0.103 \%)$, and $1.4 \mathrm{~g}$ boric acid $(0.072 \%)$. Due to differential solubility in water, each of set A and B was diluted with 50 liters of water in two small reservoir tanks. Then set A and B were mixed and diluted in 1000 liters water. This nutrient mixture was diluted with water in separate tanks to $50 \mathrm{ppm}(\mathrm{N} 1), 150 \mathrm{ppm}(\mathrm{N} 2)$ and $300 \mathrm{ppm}(\mathrm{N} 3)$. Three dosages of nutrients $(\mathrm{N} 1=50 \mathrm{ppm}=0.05 \mathrm{~g} / \mathrm{L}$, $\mathrm{N} 2=150 \mathrm{ppm}=0.150 \mathrm{~g} / \mathrm{L}, \mathrm{N} 3=300 \mathrm{ppm}=0.300 \mathrm{~g} / \mathrm{L})$ at $\mathrm{pH}$ of 5.8-6.8 were applied to brinjal plants, to examine their effect on population of whiteflies. A valve attached to each nutrient tank was set up to automatically release all concentrations of nutrients for five minutes at three times daily; 0900 a.m, 1200 p.m and 1700 p.m. Nutrient concentration was monitored daily by a portable Electric Conductor (EC) tester, DiST $3 \AA(H a n n a \AA$ Instrument) and $\mathrm{pH}$ of the solution was monitored by a pH Scan1 $1{ }^{\circledR}$ to maintain an optimum level of $\mathrm{pH}$ for plant growth (at 5.5 to 7.0 ).

\subsection{Treatments 2 (Pre-Infestation)}

\subsubsection{Infestation (Pre-Infestation) of Brinjal Plants by Whitefly}

Brinjal seedlings (3-week-old) in a seedling tray were placed in a cage measuring $50 \mathrm{~cm} \times 45 \mathrm{~cm} \times 60 \mathrm{~cm}$. Then, approximately 300 whitefly adults were collected from the stock culture and released slowly into the cage following the procedure of Inbar et al. (1999) [12]. All plants were shaken 
gently every day to ensure homogenous infestation by whitefly adults. The infested brinjal seedlings were inspected for the presence of immature stages of whitefly on the underside of leaves. After a week, 15 fully infested seedlings were randomly selected for the experiment.

\subsubsection{Infestation (Pre-Infestation) of Brinjal Plants by Aphid}

A tray of 3-week-old brinjal seedlings was kept in a cage. Ten adult aphids from the stock culture were carefully introduced manually on leaves of each brinjal seedling. After one week of infestation, a total of 15 fully infested brinjal seedlings were taken to the experimental plot.

\subsubsection{Control (Non-Pre-Infested) Brinjal Plants}

Several healthy 3-week-old brinjal seedlings free from pest infestations were placed in a cage. The plants were watered daily. After a week, 15 plants were selected for the experiment.

\subsection{Experimental Plot under Rain Shelter}

Four week-old brinjal seedlings; a) pre-infested by whitefly (TW), b) pre-infested by aphid (TA) and c) non-infested seedlings (control) were transplanted into white polyethylene bags $(30 \mathrm{~cm} \times 30 \mathrm{~cm})$ containing burnt rice husk as planting media, and placed under a rain shelter. All pre-infested plants were inspected individually under dissecting microscope to ensure successful infestation by respective pests before transplantation. Ten of each of pre-infested plants by whitefly and aphids were randomly examined. There were 5.1 larvae/leaf and 2.7 nymphs/leaf (mean number) of whitefly (immature) and aphid respectively prior to the experiment in the first crop. In the second crop, there were 4.3 larvae/leaf and 3.9 nymphs/leaf of whitefly and aphids respectively. All polyethylene bags were arranged in a Randomized Complete Block Design (RCBD) with five replications (blocks).

\subsection{Sampling of Whiteflies}

Sampling of whiteflies was conducted at biweekly interval in the morning $(0900 \mathrm{~h}$ to $1000 \mathrm{~h})$ starting from the second week after transplanting (WAT) (6 week-old plants) until the end of harvesting (12 WAT). Forty five samples were collected ( 3 nutrient levels $\times 3$ pre-infestation treatments $\times 5$ replicates) at every sampling occasion. A leaf from the middle stratum [13] of each plant was carefully inserted into a zip-lock plastic bag and the petiole severed. All stages of whiteflies on the leaf were identified and counted under a dissecting microscope in the laboratory.

\subsection{Data Analysis}

All data were transformed to meet the assumptions of normality and homogeneity of variances (Kolmogorov-Smirnov test and Levene test). Differences in biweekly mean abundance of whitefly at different levels of nutrients and different pest pre-infestations were analyzed using one -way and factorial analysis of variance (ANOVA) [14] of
Statistical Package for Social Science (SPSS). Multivariate factorial analysis of variance was carried out to determine the effects of both treatments, nutrient and pre-infestation, and time on whiteflies abundance in two cropping periods. The t-test was carried out to determine the effect of different cropping periods on the abundance of whitefly. All values were presented as means $( \pm)$ standard errors (S.E).

\section{Results}

\subsection{Influence of Nutrient Concentration and Pre-infestation of Brinjal Seedlings on Abundance of Whitefly Population}

Whitefly has been known to infest vegetable crops planted under rain shelters or in greenhouses severely. In this study heavy infestations were observed on all leaves of all plants (Table 1 and Table 2) as early as 2 WAT in both first and second crops. In both crops, infestations were high in the early stage of plant growth (2 WAT to 4WAT), decreased as the plants entered flowering stage (6 WAT), and very low at the fruiting stage ( 8 WAT to 12 WAT) when the leaves were less attractive to the pest. There was a low infestation of whiteflies on brinjal plants in the first compared to the second crops. The abundance of whitefly larvae was significantly different among all nine treatments $(\mathrm{F}=3.356$; $\mathrm{df}=8,269 ; \mathrm{P}<0.05)$ (Table 1 ) in the first cropping period. The highest mean number of whitefly larvae was recorded on aphids pre-infested plants applied with $50 \mathrm{ppm}$ (N1TA) (26.03 \pm 7.64 larvae/leaf), followed by control plants applied with 300 ppm nutrient $(\mathrm{N} 3 \mathrm{TC}=25.06 \pm 7.28 /$ leaf $)$. The lowest larval population was recorded on whitefly pre-infested brinjal plants applied with 150 ppm nutrient (N2TW). Within the period of study, the whitefly abundance was significantly different among the nine treatments at 2 WAT $(\mathrm{P}<0.01)$. At this time, whitefly pre-infested plants applied with 150 ppm nutrient (N2TW) had the lowest population (9.80 $\pm 2.60 /$ leaf), but no significant difference was observed with whitefly pre-infested plants applied with 300 ppm nutrient (N3TW). Meanwhile, N1TA and N3TC had the highest number of whitefly on the underside of their leaves. Based on Duncan Multiple Range Test (DMRT), the number of whiteflies infesting N2TW plants was different from those on N1TA, N3TA, N3TC and N2TC but no difference was detected with N2TA and N1TC.

At 4 WAT, the population of whitefly decreased dramatically in all treatments, except in pre-infested plants by whitefly treated with 50 ppm nutrients (N1TW). Similarly, the lowest infestation of whitefly was recorded on pre-infested plants by whiteflies applied with $150 \mathrm{ppm}$ nutrients (N2TW) (1.60 \pm 0.40$)$, followed by whitefly pre-infested plants treated with $300 \mathrm{ppm}$ nutrients (N3TW) (12.60 \pm 2.66$)$. Both non-infested brinjal plants applied with $50 \mathrm{ppm}$ and aphid pre-infested plants treated with $150 \mathrm{ppm}$ had low number of whiteflies $(13.60 \pm 2.8$ and $13.60 \pm 1.63$ respectively). There was a significance difference in mean number of whiteflies among the treatments at 4 WAT 
$(\mathrm{F}=3.230 ; \mathrm{df}=8,44 ; \mathrm{P}<0.01)$ (Table 2). The DMRT confirmed that N2TW had the lowest number of whiteflies among all treatments except N3TW. Populations of whitefly declined drastically after 6 WAT in all treatments. No significant difference $(\mathrm{P}>0.05)$ was recorded in mean number of whiteflies among treatments at 6 WAT $(\mathrm{P}>0.05), 8$ WAT $(\mathrm{P}>0.05), 10$ WAT $(\mathrm{P}>0.05)$ and 12 WAT $(\mathrm{P}>0.05)$. At 10 and 12 WATs, population of whitefly fluctuated slightly in all treatments. Population of whitefly sharply decreased after 4 WAT to the end of sampling period, particularly at nutrient concentrations of $150 \mathrm{ppm}$. Overall, the lowest population of whitefly was observed on pre-infested plants by whitefly at all sampling dates. Generally, the plants treated with the highest concentration of nutrient (300 ppm) had been infested with high number of whiteflies.

Table 1. Effects of three concentrations of nutrients and pre-infested plants on biweekly populations (means \pm SE) of larval whitefly in the first cropping period.

\begin{tabular}{|c|c|c|c|c|c|c|c|}
\hline Treatment & 2WAT & 4WAT & 6WAT & 8WAT & 10WAT & 12WAT & Mean/leaf \\
\hline N1TC & $23.4 \pm 4.39 \mathrm{ab}$ & $13.60 \pm 1.63 \mathrm{abc}$ & $3.60 \pm 1.69 \mathrm{ab}$ & $0.80 \pm 0.58 \mathrm{ab}$ & $0.60 \pm 0.40 \mathrm{a}$ & $1.40 \pm 0.68 \mathrm{a}$ & $7.23 \pm 1.76 \mathrm{ab}$ \\
\hline $\mathrm{N} 2 \mathrm{TC}$ & $47.80 \pm 11.50 \mathrm{~b}$ & $35.40 \pm 7.42 \mathrm{~cd}$ & $4.80 \pm 1.39 \mathrm{ab}$ & $0.80 \pm 0.80 \mathrm{ab}$ & $1.60 \pm 0.68 \mathrm{ab}$ & $1.60 \pm 0.81 \mathrm{a}$ & $15.33 \pm 4.50 \mathrm{abc}$ \\
\hline N3TC & $95.40 \pm 22.10 \mathrm{c}$ & $37.00 \pm 6.99 \mathrm{~d}$ & $14.20 \pm 6.18 \mathrm{ab}$ & $1.60 \pm 1.03 \mathrm{ab}$ & $1.80 \pm 0.66 \mathrm{ab}$ & $0.40 \pm 0.40 \mathrm{a}$ & $25.06 \pm 7.28 \mathrm{c}$ \\
\hline N1TW & $17.20 \pm 4.94 \mathrm{ab}$ & $34.40 \pm 11.91 \mathrm{bcd}$ & $1.20 \pm 0.97 \mathrm{a}$ & $0.00 \mathrm{a}$ & $3.80 \pm 1.91 \mathrm{ab}$ & $4.60 \pm 4.12 \mathrm{a}$ & $10.20 \pm 3.07 \mathrm{ab}$ \\
\hline N2TW & $9.80 \pm 2.60 \mathrm{a}$ & $1.60 \pm 0.40 \mathrm{a}$ & $4.20 \pm 1.07 \mathrm{ab}$ & $1.00 \pm 0.77 \mathrm{ab}$ & $4.80 \pm 1.91 b$ & $1.60 \pm 0.75 \mathrm{a}$ & $3.77 \pm 0.79 \mathrm{a}$ \\
\hline N3TW & $17.80 \pm 3.61 \mathrm{ab}$ & $12.60 \pm 2.66 \mathrm{ab}$ & $1.60 \pm 0.93 \mathrm{a}$ & $0.00 \mathrm{a}$ & $2.60 \pm 0.93 \mathrm{ab}$ & $2.20 \pm 1.71 \mathrm{a}$ & $6.70 \pm 1.90 \mathrm{a}$ \\
\hline N1TA & $99.80 \pm 21.25 \mathrm{c}$ & $29.60 \pm 5.94 \mathrm{bcd}$ & $23.80 \pm 14.79 b$ & $0.40 \pm 0.40 \mathrm{a}$ & $1.40 \pm 0.51 \mathrm{ab}$ & $1.20 \pm 0.37 \mathrm{a}$ & $26.03 \pm 7.64 c$ \\
\hline N2TA & $35.20 \pm 3.32 \mathrm{ab}$ & $13.60 \pm 2.80 \mathrm{abc}$ & $1.20 \pm 0.58 \mathrm{a}$ & $1.40 \pm 0.87 \mathrm{ab}$ & $3.80 \pm 2.08 \mathrm{ab}$ & $2.40 \pm 1.03 \mathrm{a}$ & $9.60 \pm 2.39 \mathrm{ab}$ \\
\hline N3TA & $52.20 \pm 12.47 \mathrm{~b}$ & $39.40 \pm 9.37 \mathrm{~d}$ & $19.40 \pm 15.76 \mathrm{ab}$ & $3.20 \pm 1.71 b$ & $1.80 \pm 1.32 \mathrm{ab}$ & $0.40 \pm 0.24 \mathrm{a}$ & $19.40 \pm 5.03 \mathrm{bc}$ \\
\hline ANOVA & $\begin{array}{l}\mathrm{F}=7.308 \\
\mathrm{df}=8,44 \\
P<0.01\end{array}$ & $\begin{array}{r}\mathrm{F}=3.230 \\
\mathrm{df}=8,44 \\
P<0.01\end{array}$ & $\begin{array}{l}\mathrm{F}=1.304 \\
\mathrm{df}=8,44 \\
P>0.05\end{array}$ & $\begin{array}{l}\mathrm{F}=1.349 \\
\mathrm{df}=8,44 \\
P>0.05\end{array}$ & $\begin{array}{l}\mathrm{F}=1.106 \\
\mathrm{df}=8,44 \\
P>0.05\end{array}$ & $\begin{array}{r}\mathrm{F}=0.629 \\
\mathrm{df}=8,44 \\
P>0.05\end{array}$ & $\begin{array}{l}\mathrm{F}=3.356 \\
\mathrm{df}=8,269 \\
P<0.05\end{array}$ \\
\hline
\end{tabular}

* Means in the column with the same letters are not significantly different at $P=0.05$ based on Duncan Multiple Range Test (DMRT). ** Week After Transplanting.

In the second cropping period, the abundance of whiteflies was significantly different among all nine treatments during the entire sampling period $(\mathrm{P}<0.01)$ (Table 2$)$. The highest number of whitefly larvae was recorded on control brinjal plants particularly those applied with $300 \mathrm{ppm}$ nutrient concentration (N3TC) $(26.03 \pm 5.92 /$ leaf $)$, followed by N1TC (20.63 $\pm 5.37 /$ leaf $)$. Similar to the first crop, the lowest larval population was observed on whitefly pre-infested plants at $150 \mathrm{ppm}$ nutrient (N2TW) with an average of $5.97 \pm 1.12$ larvae/leaf. At the beginning of the second cropping period, similar trend of whitefly infestation in the first crop was observed when more whiteflies were found on control plants. All treatments affected the abundance of whiteflies at 2 WAT $(\mathrm{P}<0.01)$ and 4 WAT $(\mathrm{P}<0.01)$.

Table 2. Effects of three concentrations of nutrients and pre-infested plants on biweekly populations (means $\pm S E$ ) of larval whitefly in the second cropping period.

\begin{tabular}{|c|c|c|c|c|c|c|c|}
\hline & 2WAT & 4WAT & 6WAT & 8WAT & 10WAT & 12WAT & Mean/Leaf \\
\hline N1TC & $67.40 \pm 15.49 \mathrm{~d}$ & $33.20 \pm 6.41 b c$ & $9.20 \pm 2.35 \mathrm{ab}$ & $6.40 \pm 1.69 \mathrm{ab}$ & $4.20 \pm 0.73 \mathrm{ab}$ & $3.40 \pm 0.75 a$ & $20.63 \pm 5.37 b c$ \\
\hline $\mathrm{N} 2 \mathrm{TC}$ & $40.40 \pm 8.29 b c$ & $9.40 \pm 3.03 \mathrm{ab}$ & $6.00 \pm 1.70 \mathrm{a}$ & $15.00 \pm 3.29 b$ & $5.60 \pm 0.87 \mathrm{abc}$ & $4.40 \pm 1.29 a$ & $13.47 \pm 2.75 \mathrm{ab}$ \\
\hline N3TC & $62.20 \pm 13.67 \mathrm{~cd}$ & $66.20 \pm 15.22 d$ & $8.80 \pm 2.52 \mathrm{ab}$ & $6.80 \pm 0.73 \mathrm{ab}$ & $7.00 \pm 1.52 \mathrm{bcd}$ & $5.20 \pm 1.39 a$ & $26.03 \pm 5.92 \mathrm{c}$ \\
\hline N1TW & $12.80 \pm 2.99 \mathrm{a}$ & $2.80 \pm 0.97 \mathrm{a}$ & $9.20 \pm 2.76 \mathrm{ab}$ & $8.60 \pm 3.75 \mathrm{ab}$ & $8.00 \pm 2.30 \mathrm{bcd}$ & $3.40 \pm 0.51 \mathrm{a}$ & $7.47 \pm 1.41 \mathrm{a}$ \\
\hline N2TW & $10.40 \pm 2.54 \mathrm{a}$ & $6.00 \pm 1.37 \mathrm{ab}$ & $7.40 \pm 2.77 \mathrm{a}$ & $3.80 \pm 1.32 \mathrm{a}$ & $4.80 \pm 1.28 \mathrm{ab}$ & $3.40 \pm 1.03 \mathrm{a}$ & $5.97 \pm 1.12 \mathrm{a}$ \\
\hline N3TW & $16.60 \pm 5.02 \mathrm{ab}$ & $47.00 \pm 17.31 \mathrm{~cd}$ & $8.60 \pm 1.50 \mathrm{ab}$ & $11.60 \pm 3.53 \mathrm{ab}$ & $0.60 \pm 0.24 a$ & $6.20 \pm 1.66 \mathrm{a}$ & $15.10 \pm 3.96 \mathrm{ab}$ \\
\hline N1TA & $15.20 \pm 3.23 \mathrm{ab}$ & $15.40 \pm 2.98 \mathrm{ab}$ & $9.80 \pm 2.75 \mathrm{ab}$ & $12.40 \pm 2.79 \mathrm{ab}$ & $6.00 \pm 2.51 \mathrm{bcd}$ & $3.40 \pm 1.03 \mathrm{a}$ & $10.77 \pm 2.76 \mathrm{a}$ \\
\hline N2TA & $3.40 \pm 1.02 \mathrm{a}$ & $12.80 \pm 3.30 \mathrm{ab}$ & $7.40 \pm 2.69 a$ & $8.60 \pm 3.09 \mathrm{ab}$ & $10.40 \pm 2.01 \mathrm{~cd}$ & $5.80 \pm 1.50 \mathrm{a}$ & $8.07 \pm 1.21 \mathrm{a}$ \\
\hline N3TA & $16.60 \pm 4.33 \mathrm{ab}$ & $6.00 \pm 1.87 \mathrm{ab}$ & $16.80 \pm 3.72 b$ & $10.80 \pm 2.60 \mathrm{ab}$ & $10.80 \pm 1.80 \mathrm{~d}$ & $6.60 \pm 2.36 \mathrm{a}$ & $11.27 \pm 1.60 \mathrm{ab}$ \\
\hline ANOVA & $\begin{array}{l}\mathrm{F}=6.416 \\
\mathrm{df}=8,44 \\
\boldsymbol{P}<\mathbf{0 . 0 1}\end{array}$ & $\begin{array}{r}\mathrm{F}=5.103 \\
\mathrm{df}=8,44 \\
\boldsymbol{P}<\mathbf{0 . 0 1}\end{array}$ & $\begin{array}{l}\mathrm{F}=1.095 \\
\mathrm{df}=8,44 \\
P>0.05\end{array}$ & $\begin{array}{l}\mathrm{F}=1.057 \\
\mathrm{df}=8,44 \\
P>0.05\end{array}$ & $\begin{array}{l}\mathrm{F}=3.151 \\
\mathrm{df}=8,44 ; \\
P>0.05\end{array}$ & $\begin{array}{r}\mathrm{F}=0.931 \\
\mathrm{df}=8,44 ; \\
P>0.05\end{array}$ & $\begin{array}{l}\mathrm{F}=3.800 \\
\mathrm{df}=8,269 \\
\boldsymbol{P}<\mathbf{0 . 0 1}\end{array}$ \\
\hline
\end{tabular}

$*$ Means in the column with the same letters are not significantly different at $P=0.05$ based on Duncan Multiple Range Test (DMRT). ** Week After Transplanting.

Whitefly pre-infested plants suffered low whitefly infes- 
(pre-infested plants by whitefly supplied with 150 ppm nutrient) recorded the lowest number of whiteflies $(10.40 \pm 2.54)$ in both cropping periods. Meanwhile, both N1TC and N3TC had the highest abundance of whitefly. However, there was no significance difference of whitefly abundance in N2TW compared to whitefly or aphid pre-infested plants receiving various nutrient concentrations.

At 4 WAT, the population of whitefly decreased considerably in most treatments, except on plants that received 300 ppm nutrients concentration such as N3TC and N3TW. Low whitefly infestation were observed mostly on pre-infested plants by whiteflies particularly N1 TW (50 ppm; $2.80 \pm 0.97)$ and N2TW (150 ppm; 6.00 \pm 1.37$)$, followed by N3TA (300 ppm; aphid pre-infested) (6.00 \pm 1.87$)$. N2TC and N2TA also suffered low infestations with $9.40 \pm 3.03$ and $12.80 \pm 3.30$ larvae per leaf respectively (Table 2 ). The populations of whitefly were considerably low after 6 WAT in all treatments and the population abundances were not significantly different $(\mathrm{P}>0.05)$ among treatments at 6 WAT $(\mathrm{P}>0.05), 8$ WAT $(\mathrm{P}>0.05), 10$ WAT $(\mathrm{P}>0.05)$ and 12 WAT $(\mathrm{P}>0.05)$. Whitefly populations fluctuated slightly in most treatments from 8 WAT to the end of sampling period (12WAT). Similar to the first cropping period, populations of whitefly sharply decreased from 4 WAT to the end of study, especially those applied with $150 \mathrm{ppm}$ nutrient concentrations. Whitefly pre-infested plants consistently suffered the lowest infestations by whitefly. In general, plants applied with the highest $(300 \mathrm{ppm})$ nutrients concentrations were strongly preferred by whiteflies at initial growing stages (up to 4 WAT) in both cropping periods. In this study, the effects of various treatments on whitefly infestation on brinjal plants were assessed for two cropping periods. The result shows that the whitefly populations are significantly different $(\mathrm{P}<0.05)$ in the two cropping periods. Whitefly populations were not significantly different in the two cropping periods which implied consistent population abundances on brinjal plants receiving similar treatments in both crops. Treatments N2TW and N3TC had the lowest and highest whitefly populations in both cropping periods respectively.

Based on multivariate analysis of variance (MANOVA) in the first cropping period, there was no difference in abundance of whiteflies infesting brinjal plants applied with 50, $150 \mathrm{ppm}$ and $300 \mathrm{ppm}$ nutrient concentrations at $\mathrm{P}>0.05$. Differences in plants vigor as they responded to increasing amount of nutrients during the cropping period did not influence the abundance of whitefly infesting the plants $(\mathrm{Nu}-$ trient concentration $*$ time, $\mathrm{P}=0.737$ ). In this case the null hypothesis of equal mean of whitefly abundances among the three nutrient levels applied to the plants was accepted. The plants responded to pre-infestations by whiteflies and aphids differently as whiteflies abundances on plants infested by the two pest species varied significantly $(\mathrm{F}=5.919 ; \mathrm{df}=2,216$; $\mathrm{P}<0.01$ ). In relation to time of plant growth (phenology) effect, the abundances of whiteflies also varied significantly as brinjal plants were growing from vegetative to flowering and fruiting phases (from 2 WAT to 12 WAT) $(\mathrm{F}=29.501$; $\mathrm{df}=5,216 ; \mathrm{P}<0.01)$. Whitefly abundances showed no significance difference in response to compounded interactions of nutrient levels and pre-infestations of brinjal seedlings as plants grew to maturity (time).

In the second crop, mean abundances of whitefly population were significantly different in plants receiving different concentrations of nutrients $(\mathrm{F}=9.068 ; \mathrm{df}=2,216 ; \mathrm{P}<0.01)$ and whitefly as well as aphids pre-infested brinjal seedlings $(\mathrm{F}=18.508 ; \mathrm{df}=2,216 ; \mathrm{P}<0.01)$. The abundances also varied as plants grew to maturity (bearing fruits) at the end of the cropping period $(\mathrm{F}=22.624 ; \mathrm{df}=5,216 ; \mathrm{P}<0.01)$. Except for no interaction between the concentrations of nutrients applied to the plants and pest pre-infestations of the seedlings, other interactions were observed thus consequently affecting the abundances of whitefly infesting the plants.

\subsection{Effect Different Concentrations of Nutrients on Ab- undance of Whitefly Population on Brinjal Plants (Control)}

The effect of nutrient concentrations applied to brinjal plants on whitefly population was examined in the control brinjal plants (TC) which were not infested by any of the two pests, whitefly or aphid. During the first cropping period, whitefly populations varied significantly among treatments $(\mathrm{P}<0.05)$ at 2 WAT. However, at 4 WAT until 12 WAT, the population did not show any significance difference $(\mathrm{P}>0.05)$ among all nutrient concentrations. Further investigation by the multiple mean comparisons showed that whitefly abundance was lower in N1TC compared to N3TC but there was no difference with N2TC. Meanwhile, population in N2TC was different from N3TC. N3TC harbored the highest number of whitefly larvae $(25.06 \pm 7.28)$ and the population decreased corresponding to decreasing in nutrient concentrations from N2TC to N1TC. Whitefly populations were constantly higher on plants receiving higher nutrient concentration $(300 \mathrm{ppm})$ particularly at 2 WAT and 4 WAT. Nevertheless the populations decreased to very low level from 6 WAT onwards in all nutrient concentrations (N1TC, N2TC and N3TC) with less than 5.0 larvae/leaf. In the second crop, abundance of whitefly was significantly different among the plants receiving three nutrient concentrations $(\mathrm{P}<0.01)$ at 4 WAT. From then on no difference of whitefly abundance was detected until the end of sampling week. Similar to the first crop, the highest abundance of whitefly was recorded on plants applied with $300 \mathrm{ppm}$ nutrient concentration (N3TC) $(26.03 \pm 5.92 /$ leaf $)$, followed by N1TC $(20.63 \pm 5.37 /$ leaf $)$ and the least was on N2TW (13.47 \pm 2.75$)$. Meanwhile, at 2 WAT, N1TC had the highest number of whitefly compared to other treatments. At 4 WAT, N2TC recorded the lowest number of whitefly with $9.40 \pm 3.03 /$ leaf. From 6 WAT onwards, the population of whitefly decreased in all treatments.

\subsection{Effect of Different Concentrations of Nutrients on Abundance of Whitefly Population on Whitefly Pre-Infested Brinjal Plants (N1TW, N2TW and N3TW)}


In general, the infestation of whitefly on whitefly pre-infested brinjal plants did not vary very much in all nutrient treatments throughout the study. However, the abundances of whitefly populations were significantly different at 4 WAT in the first $(\mathrm{P}<0.05)$ and second cropping periods $(\mathrm{P}<0.05)$ as well as at 10 WAT of the second cropping period $\left(\mathrm{F}_{2,14}=5.903, \mathrm{P}<0.05\right)$. Among the three levels of nutrient concentrations applied to the plants $(\mathrm{N} 1 \mathrm{TW}=50$ ppm, N2TW=150 ppm and N3TW=300 ppm) in the first cropping period, N2TW had the lowest population of whitefly (3.77 \pm 0.79 larvae per leaf) and the highest was recorded on N1TW $(10.20 \pm 3.07)$ especially at 2 WAT (9.80 \pm 2.60$)$, (although not significantly different at $\mathrm{P}<0.05$ ), 4 WAT $(1.20 \pm 0.49)$, followed by N3TW (12.60 \pm 2.66$)$. Interestingly, the population of whitefly declined as early as 6 WAT and continued onwards in all nutrient concentrations. Similar to the first cropping period, the lowest larval population in the second crop was also observed on plants receiving $150 \mathrm{ppm}$ nutrient (N2TW) but the highest was in N3TW with an average of $5.97 \pm 1.12$ larvae/leaf and $15.10 \pm 3.96 /$ larvae/leaf respectively. At initial stage of sampling (2 WAT), N2TW (150 ppm) had the lowest number of whiteflies (10.40 \pm 5.19$)$. At 4 WAT, whitefly populations started to decline in all nutrient treatments except in N3TW. The populations dropped during the subsequent weeks until the end of sampling week (12 WAT).

\subsection{Effect of Different Concentrations of Nutrients on Abundance of Whitefly Population on Aphid Pre-Infested Brinjal Plants (N1TA, N2TA and N3TA)}

Whitefly populations were significantly different among aphid pre-infested plants at different level of nutrient concentrations in the first cropping period particularly at 2 WAT $(\mathrm{P}<0.05)$ and 4 WAT $(\mathrm{P}=0.05)$. For the entire sampling period (WAT 2 to 12), the Table 1 shows that the highest number (mean) of whitefly larvae was recorded on plants applied with 50 ppm (N1TA) followed by 300 ppm (N3TA) with total mean of $26.03 \pm 7.64$ larvae/leaf and $19.40 \pm 5.03$ larvae/leaf respectively. At $150 \mathrm{ppm}$ nutrient application, the number of whitefly was the lowest $(9.60 \pm 2.39$ larvae/leaf). The population of whitefly was more dominant with the highest number recorded on N1TA $(99.80 \pm 21.25$ larvae/leaf) and the least in N2TA. Whitefly population sharply decreased in all treatments (N1TA, N2TA and N3TA) from 4 WAT to 6 WAT. Tremendous declined in whitefly population was observed at 8 WAT and maintained at very low level until the end of study. There was no significance difference in the number of whitefly among nutrient treatments at every sampling occasion in the second cropping period except on 6 WAT. Table 2 shows that N3TA was the most preferred by the whiteflies (11.27 larvae/ leaf) when compared among the three treatments for the entire cropping period. The whitefly population was very low compared to the first crop. However, relatively high number of whitefly infested N3TA at 2 WAT. Small fluctuations of whitefly population were observed throughout the cropping period which led to the assumption that early infestation of aphid on brinjal plants did not affect whitefly infestation on the plants.

\section{Discussion}

Brinjal plant is one of 500 host plants for whitefly which provides good oviposition site as well as food sources for the pest. High abundances of whiteflies were recorded on brinjal plants just after the plants were transplanted (at 2 WAT). More pests were found on plants receiving higher amount of nutrients. Good plant growth and high plant quality (vigor) attracted more pests to the plants [7]. Plants that contain different compositions of varied amount of nutrients [15] absorb these nutrients from the planting medium. Availability of nutrients from the planting medium is very crucial for plant growth [16]. Whitefly, B. tabaci, infestation is influenced by different nutrient contents provided by the host plants that affect its oviposition, longevity, developmental time (from egg to adult) and mortality rates [17]. Bogran and Heinz (2000) [18] found that whiteflies select the plants with higher amounts nutrients and their population multiplies faster due to high fecundity (66 and 400 eggs) and longer longevity (10 to 60 days) of the females. High numbers of whitefly immature (such as eggs, larvae and pupae) were found scattered all over the underside of leaves [2] particularly during early growth of the plants. Similarly, in this study, the amount of nutrients supplied to the plants significantly influenced the populations of whiteflies at very early stages of plant growth (2WAT and 4 WAT). However, after these periods, its effect was negligible regardless whether the plants suffered from early infestations of other pests or by whitefly itself. This study also demonstrated that infestation of whiteflies was more restricted to early growth of brinjal plants and the pest was less harmful at other stages of plant growth.

In this study the whitefly preferred to oviposit on the plants supplied with the highest nutrient concentration (300 ppm) and lower population was observed on plants receiving the lowest nutrient $(50 \mathrm{ppm})$ concentration. Plants receiving higher amount of nutrients produce more young and vigorous leaves that provide high opportunity for whitefly to lay their eggs [8]. In addition, whiteflies living on healthy plants (high nutrient content) develop specific biological characteristics such as short life cycle, high fecundity and longevity [Mohd Rasdi, 2005 and Zurina et al., 2010] found that variations in plants' growth performance in response to various nutrient levels have changed the pest populations on the plants. The results of this study demonstrated the preference of whitefly adults for plants with higher amount of nutrient content in the leaves [6] for the survival of their progenies. Obviously control and aphids pre-infested plants receiving the highest dose (300 ppm nutrient concentration) were more preferred by whiteflies. In an earlier study, Zurina et al. (2010) [8] also reported that high doses of nutrient (nitrogen) significantly increased B. tabaci population on brinjal plants as compared to lower doses. Whiteflies extracted available amount of nutrient from the plants efficiently using specific techniques of pre and post-ingestive 
[19]. Moreover, according to William et al. (2002) [6], survival of herbivory insects improves when the nitrogen content in their bodies was approximately $15 \%$ lower than the amount available in the host plants.

However, whitefly population levels decreased in all treatments starting from 6 WAT (plants starting to flower) until end of sampling period. Several factors could cause the decline in whitefly population such as increasing number of natural enemies, poor weather condition and development of plant chemical defense [12] when plants react towards insects' feeding [11]. Similar trend was reported by Zurina et al. (2010) [8] that whitefly population was significantly higher during early season and gradually declined as the crop growth progressed. Naturally, plant vulnerability to insect-pest attack changes as it ages [20]. According to Prabhu et al. (2009) [10], brinjal plants are able to induce effective chemical defense that affect the pest population when the infested plants reach mature stage. On the other hand, the whiteflies might be attacked by their natural enemies that have established their populations in the field during the later periods of plant growth. As a response to pest infestation, the plant has the ability to induce direct and indirect defense mechanism which provides specific signals or cues to attract predators and parasite [21] to the plants. The population dynamics of whitefly was highly influenced by pre-infestation of brinjal plants by whiteflies during their seedling stage. They quickly reacted and responded against whiteflies thus dampened whitefly population as the plants' maturity increased. In relation to chemical defense produced by plants, many studies have also reported that leaves of different ages differ in their degree of herbivore's infestation [22]. This is because the production pathogenesis related proteins (PR) (chemical defense) are closely related to the development and leaf age of the plants [23]. According to Hamady et al. (2011) [22] mature leaves of Solanum lycopersicon have exhibited high activity of plant defense protein after infested by whiteflies. However, the infection of Tomato Yellow Leaf Curl Virus (TYLCV) is not influenced by leaf age. Fagoonee and Toory (1983) [24] also reported that leaves of various ages had different degree of herbivore's infestation as well as oviposition preference.

Excessive amount of nutrients applied to the plants encouraged more whiteflies to the host plants. As observed in this study, application of nutrient concentration at a recommended rate $(150 \mathrm{ppm})$ showed less whitefly infestation while plants were still able to grow healthily. Most herbivorous insects prefer highly nutritious food when they have choices [25] although such tendency was not clearly observed in Diaprepes abbreviates [26]. For this matter, doses and concentrations of fertilizer application need proper consideration for prevention of severe pest attack. The effects of various treatments on populations of whiteflies infesting brinjal plants were not detected in the first cropping period. However significant influence and interactions of nutrient concentrations, pest pre-infested plants and plant growth were observed in the second crop. A couple of factors were presumed to take effect in the second cropping period. Firstly, the presence of high competitor aphids population in the second crop, could affect the whitefly population directly and indirectly [7]. Secondly, differential production of secondary metabolites in both cropping periods as plant defense mechanisms [10] led to variation in pest-plant interactions. Other factors such as differential activities of natural enemies could contribute to variations of pest-plant responses [29].

Brinjal plants supplied with the highest (300 ppm) nutrient concentration were found to be more preferred by whiteflies and the lowest number was recorded on plants receiving lower nutrient concentration especially during early stage of plant growth (2 WAT and 4 WAT). Similar trend of whitefly population was reported by Bi et al. (2001) [30] in his study on whiteflies infesting cotton. Higher whitefly populations are observed on cotton plants receiving high nitrogen fertilization. As mention previously, plants respond to higher amount of nutrients by producing more leaves, branches and bigger size of leaves, and preferable $\mathrm{pH}$ of leaf sap [31] thus providing more food resources to the pest. Close-hairy characteristics of young leaves is a favorable condition for female whiteflies to lay their eggs [3] as this will secure the progeny from hazardous effect of heavy wind and rainfall. At initial stage of plant growth, flushing of young leaves support active feeding by voracious immature whiteflies which is crucial for establishment of whitefly population.

Nutrient composition supplied to the plants in this study is one of the optimal solutions recommended by MARDI (Malaysian Agriculture Research and Development Institute) and DOA (Department of Agriculture) Malaysia. Plants growth performance is better when they are supplied the right amount of nutrients (150 ppm and $300 \mathrm{ppm})$. Reddy and Venugopal Rao (1989) [32] reported that the optimum nutrient (nitrogen) content of the host plant is associated with plant resistance against whitefly. However, the result of this study showed that plants receiving excessive amount of nutrient concentration such as at 300 ppm, were severely infested by whiteflies. This trend of pest infestation also has been previously reported by Jauset et al. (1997) [33], who observed higher whitefly population on crop supplied with high dosages of fertilizer than the non-fertilized crop. According to Bentz et al. (1995) [34], nutrient levels (Nitrogen) supplied to the plants can increase the quality [35] of nutrient in the host plant such as increasing nitrogen level in leaf that will interfere with natural plant resistance mechanisms. It increases the fertility and acceptance of female whiteflies to oviposit [36] thus increases the plant's susceptibility to the pest. Low whitefly abundance on plants receiving low nutrient concentration (50 ppm), was probably related to insufficient nutrients in brinjal leaves which was unfavorable for the development of whitefly progenies [37] consequently caused high mortality. Meanwhile, the decline in the number of whiteflies at the end of the growing seasons corresponded with maturing plants with reduced nitrogen absorption hence were more resistant to whitefly infestation [8]. 
When the brinjal plants were exposed to early infestation by its pest (whitefly), most plants consistently recorded lower number of whiteflies on them especially at the early part of plant growth. This was more obvious on plants that received $150 \mathrm{ppm}$ (optimum nutrient concentration) which consistently recorded the lowest number of whitefly in both cropping periods. Whitefly inserts enzymes into the host plant while feeding which affects the normal physiological growth processes of the host plants [2] and subsequently triggers chemical defense. This indicated that plants with early infestation by whitefly may have produced chemical defense [38] earlier than the control plants (without pre-infestation). Whitefly infestation rate was high on pre-infested plants that received high nutrient concentration (300 ppm). In this case, nutrient concentration supplied to the plants probably influenced plants' volatiles by either increasing or decreasing their amounts in the plants after infestation. Ibrahim et al. (2007) [39] reported that the induction of plant volatiles such as (Z)-3-hexen-1-ol, (Z)-3-hexenyl acetate and b-elemene was significantly higher in infested plants grown in a high-nutrient soil compared to infested plants in a low-nutrient soil. Generally, this study found that early infestation by whitefly and different levels of nutrient applied to brinjal plants in the field had contributed to the changes of whitefly population trend [9]. Whitefly population declined early in plants pre-infested by whitefly than in control plants with higher number at early stage of plant growth. Takabayashi et al. (1991) [40] reported that brinjal plants produced mixtures of volatiles and stimulated chemical defense after being infested by whitefly [22] for at least 7 days [12]. However, after eight weeks (WAT), all plants in all treatments including control plants had very low abundance of whiteflies but more drastic decrease was observed in plants pre-infested by whitefly than in control plants as plant grew from vegetative stage to fruiting stage. Some forcing factors, for instance, modifications of nutrient management [41], trophic interaction especially natural enemy and competitor pest [42] could play roles in regulating the whitefly populations.

Aphids pre-infested brinjal plants treated with $50 \mathrm{ppm}$ nutrient concentration were found to have the highest number and were more preferred by whiteflies at early stage of plant growth ( 2 WAT and 4 WAT) in both cropping periods. There was no clear relationship between nutrient concentration and whitefly infestation at three levels of nutrients applied to the plants in aphid pre-infested plants. The result had an agreement with Borowicz et al. (2003) [26] who reported that different levels of fertilizer supplied to the host plants did not influence herbivore's performance.

Interestingly, this study found that whitefly less preferred the plants receiving optimum amount of nutrient supply (150 ppm). While, on low nutrient plants pre-infested by aphid, whitefly infestation was higher and they showed high competitive activity. Good performance and very healthy plants that could resist pest infestation was observed at this optimum nutrient level (150 ppm). This is supported by previous findings [45] who reported that the pest feeding rates and infestation change in response to different nutrient rates applied to the plant (peas).

This study indicated that early infestation by aphid did not affect whitefly population on the aphid pre-infested plants especially at early stage of plant growth. It also can infer that early aphid infestation on the brinjal plants, may or may not trigger chemical defense but it seems not affecting the whitefly infestation. Furthermore, Dicke and van Loon (2000) [43] reported that the quantity and composition of volatiles released by plants could be different for different pest species [20]. Generally, whitefly tends to compete with aphids [10] for oviposition site on aphid pre-infested plants. At the same time, whitefly prefers to co-exist with its competitor (aphids) for its survival and security against parasitoids. Previous study reported that aphids are more preferred preys by whitefly's parasitoids such as Encarsia formosa [44]. Principally, whitefly is considered as a major pest of brinjal since it is highly capable to compete, resistant to aphid pre-infestation effect and having a good strategy in reducing parasitism activity on itself to sustain its population

\section{Conclusions}

Plant growth, nutrient concentration and early infestation by whitefly on the brinjal plants could affect whitefly population considerably. Populations of whitefly were higher following increasing levels of nutrients in non-pre-infested plants, however, the lowest populations were observed on whitefly pre-infested brinjal plants. It can be concluded that whitefly was more dominant and able to resist whitefly infestation to some extent.

\section{Acknowledgements}

We were grateful to the School of Biological Sciences, Universiti Sains Malaysia (Research grant: 1001/PBIOLOGI/844053) and Department of Agricultural Station, Relau in Penang for providing the experimental sites and other facilities to undertake this study. Thanks to anonymous referees who had tremendously improved the earlier version of the manuscript.

\section{References}

[1] Gennadius P (1889) Disease of tobacco plantations in the Trikonia. The Aleyrodid of tobacco, Ellenike Georgia 5. 1-3.

[2] McDonough MJ, Daniel G and Mark EA (2003) Whiteflies in Commercial Greenhouse Poinsettia Production. Reagents of the University of Minnesota. 1-12.

[3] Mohd Rasdi Z (2005) Biology, distribution and effect of selected insecticides against whiteflies (Trialeurodes vaporariorum Westwood and Bemisia tabaci Gennadius) on brinjal (Solanum melongena). Thesis; Universiti Teknologi MARA, Malaysia.

[4] Dung NH and Thanh Dung TT (2003) Economic and health 
consequences of pesticide use in paddy production in the Mekong Delta, Vietnam. Research Report: 1-39.

[5] Swain T (1977) Secondary compounds as protective agents. Annual Review of Plant Physiology, 28: 479-501.

[6] William FF, Evan S, Charles M, Robert FD, Andrea FH, Athur WH and James JE (2002) Nitrogen in insects: Implications for trophic complexity and species diversification. The American Naturalist, Vol.160 (6) Dec 2002.

[7] Teja T and Bradford AH (2000) Multitrophic level interactions: an introduction. Cambridge University Press.

[8] Zurina M, Mohamad Roff MN and Idris AB (2010) Effect of nitrogen rates on the whitefly Bemisia tabaci) population infesting chilli (Capsicum annum L.). Sains Malaysiana, 39(6): 913-920.

[9] Yolanda HC and Stepen CW (2005) Crop domestication disrupts a native tritrophic interaction associated with the sunflower, Helianthus annuus (Asterales: Asteraceae). Ecological Entomology (2005) 30: 673-683.

[10] Prabhu M, Natarajan S, Veeraragavathatham D and Pugalendhi L (2009) The biochemical basis of shoot and fruit borer resistance in interspecific progenies of brinjal (Solanum melongena). EurAsian Journal of BioSciences, 3: 50-57.

[11] Mohd Rasdi Z and CheSalmah MR (2011) Multitrophic system: Effect of different concentration of nutrient and pre-infested brinjal (Solanum melongena) on whitefly (Bemisia tabaci) population. 2011 3rd International Symposium \& Exhibition in Sustainable Energy \& Environment, 1-3 June 2011, Melaka, Malaysia. 236-242.

[12] Inbar M, Doostdar H, Leibee GL and Mayer RT (1999) The role of plant rapidly induced responses in asymmetric interspecific interaction among herbivores. Journal of Chemical Ecology, Vol. 25, No. 8, 1999.

[13] Mohd Rasdi Z, Fauziah I, CheSalmah MR, Fairuz K, Saiful Akbar MS, Md Jamaludin B and Kamaruzaman J (2009). Population ecology of whitefly, Bemisia tabaci, (Homoptera: Aleyrodidae) on brinjal. Journal of Agricultural Science (CCSE). Vol. 1 (1): 27-32.

[14] Sandra DS, Ramon CL (1987) SAS System for Elementary Statistical Analysis. SAS Institute Inc. 418 pp.

[15] Schoonhoven LM, van Loon JJ A and Dicke M (2005) Insect-plant biology. Oxford: University Press. pp. 421.

[16] Gershenzon J and Croteau R (1991) Terpenoids. In: Rosenthal GA and Berenbaum MR, Herbivores: Their Interaction With Secondary Plant Metabolites. CRC Press, Boca Raton, FL: $165-219$.

[17] Lenteren JC, Van LP and Noldus JJ (1990) Whitefly-plant relationships: Behavioural and ecological aspects. In: Whiteflies: Their bionomics, pest status and management, D. Gerling (ed.). Intercept, Hants, United Kingdom, pp. 47-90.

[18] Bogran CE and Heinz KM (2000) Whiteflies: House and landscape pests. Texas Cooperative Extension; B-6127.

[19] Spencer TB (2008) Insect herbivore nutrient regulation. Annual Rev. Entomol.2009. 54:165-187.

[20] Gibson RW (1971) The resistance of three Solanu species to Myzus persicae, Macrosiphum euphorbiae and Aulacorthum solani (Aphididae: Homoptera). Ann. Appl. Biol. 68. pp.
$245-251$.

[21] Walling LL (2000) The myriad plant responses to herbivores. Department of Botany and Plant Sciences, J Plant Growth Regul (2000) 19:195-216.

[22] Hamady D, Tomomitsu S, Ahmad Abu, Al Thbiani A, Ronald EM, Suhaila AH, Fumio M and Sazaly A (2011) Peroxidase activity after viral infection and whitefly infestation in juvenile and mature leaves of solanum lycopersicum. Journal Phytopathol@2011 Blackwell Verlag GmbH.

[23] Cevahir G, Yentu“ r S, Yazgan M, U“ nal M and Yilmazer N (2004) Peroxidase activity in relation to anthocyanin and chlorophyll content in juvenile and adult leaves of “mini-star" Gazania splendens. Pak J Bot 36:603-609.

[24] Fagoonee I and Toory V (1983) Preliminary investigation of host selection mechanisms by the leafminer Liriomyza trifolii. Insect Sc. Application 4: pp. 337-341.

[25] Bernays EA, Bright KL, Gonzales N and Angel J (1994) Dietary mixing in a generalist herbivore: tests of two hypotheses. Ecology 75:1997-2006.

[26] Borowicz VA, Albrecht U and Mayer R.T (2003) Effects of nutrient supply on citrus resistance to root herbivory by Diaprepes abbreviatus L.(Coleoptera: Curculionidae). Environmental entomology 32, 1242-1250.

[27] Horowitz AR, Podoler H and Gerling D (1984) Life table analysis of the tobacco whitefly Bemisia tabaci (Gennadius) in cotton fields in Israel. Acta Ecological/Ecologia Applicata 5. pp. 221-233.

[28] Dyer LA (2007) Tropical tritrophic interactions: Nasty hosts and ubiquitous cascades. Tropical forest community ecology: 275-293.

[29] Chen Luo and Tong-Xian Liu (2011) Fitness of Encarsia sophia (Hymenoptera: Aphelinidae) parasitizing Trialeurodes vaporariorum and Bemisia tabaci (Hemiptera: Aleyrodidae). Insect science, 18: 84-91.

[30] Bi JL, Ballmer GR., Hendrix DL, Henneberry TJ and Toscano NC (2001) Effect of cotton nitrogen fertilization on Bemisia argentifolii populations and honeydew production. Entomologia experimentalist et applicata, 99 (1), 25-36.

[31] Berlinger MJ (1986) Host plant resistance to Bemisia tabaci. Agric. Ecosystems Environ. 17. pp. 69-82.

[32] Reddy AS and Venugopal Rao N (1989) Cotton whitefly (Bemisia tabaci Genn.) A review. Indian Journal of Plant Protection 17: 171- 179.

[33] Jauset AM (1997) Cytology and physiology of silverleaf whitefly-induced squash silverleaf. Exp. Appl. 46: 227-242.

[34] Bentz JA, Reeves J, Barbosa P and Francis B (1995) Nitrogen fertilizer effect on selection, acceptance and suitability of Euphorbia pulcherrima (Euphorbiaceae) as host plant to Bemisia tabaci (Homoptera: Aleyrodidae). Environmental Entomology 24: 40-45.

[35] Rote NB and Purr SN (1992) Effects of fertilizer application on incidence of whitefly on diffe different cotton cultivars. Journal of Maharashtra Agricultural Universities 17: 45-48.

[36] Mattson, W. J. Jr., (1980) Herbivory in relation to plant nitrogen content. Annual Review of Ecology and Systematic 11: $119-161$. 
[37] Liu, T. X. \& Stansly, P. A. (1995) Oviposition by Bemisia argentifolii (Homoptera: Aleyrodidae) on tomato: effects of leaf factors and insecticide residues. J. Econ. Entomol. 88: 992-997.

[38] Mayer RT, McCollum TG, McDonald RE, Polstan JE and Doostdar H (1996) Bemisia feeding induces pathogenesis-related proteins in tomato. Taxonomy, biology, damage, control and management. Androver: Intercept Ltd. 179-188.

[39] Ibrahim MA, Stewart-Jones A, Pulkkinen J, Poppy GM and Holopainen JK (2007) The influence of different nutrient levels on insect-induce plant volatiles in Bt and conventional oilseed rape plants. Plant Biology. 10: 97-107.

[40] Takabayashi J, Dicke M and Posthumus MA(1991) Variation in composition of predator-attracting allelochemicals emitted by herbivore-infested plants: relative influenced of plants and herbivore. Chemoecology 2: 1-6.

[41] Luong Minh C, Hoang Due C, Phan Thi B, Luong Thi P, Jiaan C and Heong KL (2003) Impacts of nutrient manage- ment on insect pests and diseases of rice. Journal Omonrice 11:93-102.

[42] Miller TEX (2008) Bottom-up, top-down, and within-trophic level pressures on a cactus-feeding insect. Journal Ecological Entomology, 33: 261-268.

[43] Dicke M and Joop van Loon JA (2000) Multitrophic effects of herbivore-induced plant volatiles in an evolutionary context. Entomologia Experimentalis et Applicata 97: 237-249.

[44] Sanderson JP (1996) Management of aphids and whiteflies. Proceedings for the Twelfth Conference on Insect and Disease Management on Ornamentals, San Francisco, CA. Society of American Florist, Alexandria, VA. pp. 109-124.

[45] Mittler TE (1967) Effect of amino acid and sugar concentration on the food uptake of the aphid Myzus persicae. Ent. exp. \& appl. 10 (1967): 39-51. 